\title{
EL IMPACTO EUROPEO Y AMERICANO DE LA PROCLAMACIÓN DE LA CONSTITUCIÓN DE CÁDIZ EN 18201
}

\author{
Ramon Arnabat Mata ${ }^{2}$ \\ Grupo de investigación ISOCAC - Universitat Rovira i Virgili
}

\section{RESUMEN}

La segunda proclamación de la Constitución de Cádiz el año 1820 tuvo una enorme repercusión en Europa y América, tanto por las adhesiones que recogió, como por las muestras de rechazo que obtuvo. Analizamos en este texto las diversas reacciones a la revolución española de 1820 que se produjeron entre los gobiernos y la población europea y americana durante el Trienio Liberal (1820-1823). El análisis se realiza a partir de fuentes primarias, mayoritariamente de tipo diplomático, pero también de carácter particular, localizadas en diversos archivos españoles y europeos, así como la prensa y la publicística del momento.

PALABRAS CLAVE: Constitución de Cádiz, Europa, América, revolución española, Trienio Liberal

\footnotetext{
1 Este trabajo es una versión revisada y muy ampliada del publicado en el volumen REPETO, Diana (ed.): Las Cortes de Cádiz y la Historia parlamentaria, Cádiz, Universidad de Cádiz, 2012, pp. 193-203.

2 Grupo de investigación consolidado "Ideologies i Societat a la Catalunya Contemporània" (ISOCAC). 2009 SGR 1390
} 


\section{ABSTRACT}

The second proclamation of the Constitution of Cadiz in 1820 had an enormous repercussion in Europe and America, not only by the accessions collected, but also by the rejection obtained. We analyze in this paper the various reactions, both in the government and popular level, to the Spanish revolution of 1820 that took place in Europe and America during the Liberal Triennium (1820-1823). The analysis is based on primary sources, mostly diplomatic, but also of a particular nature, located in different Spanish and European archives, such as contemporary press and publicity.

KEYWORDS: Constitution of Cadiz, Europe, America, Spanish revolution, Liberal Triennium

La segunda proclamación de la Constitución de Cádiz el año 1820 tuvo un enorme impacto en Europa y América, tanto por las adhesiones que recogió, como por las muestras de rechazo que obtuvo ${ }^{3}$.

\section{EL IMPACTO EN EUROPA}

\section{El desconcierto europeo en 1820}

La revolución española de 1820 actuó como una chispa que podría, y parcialmente así fue, encender la llama constitucional en la Europa de la Restauración diseñada en el Congreso de Viena por la Santa Alianza. Para el príncipe de Metternich, estratega de la Restauración europea, la revolución española de 1820 era peor que la francesa de 1789, ya que mientras esta tenía un carácter local, aquella tenía un carácter europeo 4. Lo confirmaba el nuncio en Viena, P. Leardi: 'E' inesprimibile l'impressione profonda che hanno fatto sull' animo di S.M.I. e R., e S.A. il Sigr. Principe' Metternich le ultime notizie della Spagna"5. El mes de abril de 1820, el embajador español en Berlín, Pascual Vallejo, afirmaba que "el objeto exclusivo de la atención general" en las tertulias de los embajadores europeos era España, ya que, según decían, "de su suerte dependía en gran parte la tranquilidad de la Europa, y aún la del mundo entero"6. Resumiendo, gran preocupación en las potencias absolutistas que dominaban Europa, sobre todo durante los primeros meses de 1820, cuando los acontecimientos no permitían prever

\footnotetext{
3 Para el Trienio Liberal ver GIL NOVALES, Alberto: Las Sociedades Patrióticas (1820-1823). Las libertades de expresión y de reunión en el origen de los partidos políticos, 2 vol., Madrid, Tecnos, 1975; y ARNABAT, Ramon: El trienni liberal i la revolució de 1820 a Catalunya, Vic, Eumo, 2001.

4 Véase DE BERTIER De SAUVIGNY, Guillaume: Metternich et la France après le Congrès de Vienne, vol. II Les Grands Congrès 1820-1824, Paris, Hachette, 1970, p. 600.

5 Despacho n $^{\circ} 426$ de 29 de marzo de 1820 dirigido al secretario de Estado de la Santa Sede. Reproducido en DÍAZ DE CERIO, Francisco: Informes y noticias de los nuncios en Viena, París y Lisboa sobre la España del siglo XIX (1814-1846), vol. I, Roma, Instituto Español de Historia Eclesiástica, 1990, p. 32.

6 Carta al Secretario del despacho de Estado con fecha de 18 de abril de 1820. Archivo Histórico Nacional (AHN), sección Estado, legajo 2.983. Si no se dice lo contrario los textos reproducidos en este apartado corresponden a este mismo fondo documental.
} 
como evolucionaría el levantamiento de Riego y la movilización de las ciudades que le fueron dando su apoyo, ni cuál sería el papel que le tocaría jugar al rey

En Francia el proceso revolucionario español fue seguido con mucho interés, tal y como reconoció en sus memorias el exministro francés Étienne-Denis Pasquier: "la triomphe allait servir d'encouragement à toutes les révoltes militaires que l'esprit aventureux du temps rendait possible"8. El gobierno francés estuvo informado del día a día de la revolución en España, tanto de forma oficial mediante sus embajadores y cónsules, como mediante espías que, bajo la cobertura comercial, se establecieron en España. Las notas de los embajadores franceses en Madrid, Laval-Montmorency y Sabatier De Cabré, presentaban la revolución española con tintes alarmantes ${ }^{9}$. Y lo mismo hacían los informes del negociante francés Louis Pêche desde el norte de España ${ }^{10}$. No es nada extraño, pues, que el gobierno francés fuese el primero en tomar medidas tendentes a proteger a su país del "contagio" revolucionario, especialmente en la frontera pirenaica y en les ciudades de Bayona y Perpinyà donde se instalaron los Commissariats Générales de la Police ${ }^{11}$. Por contra, diversos sectores de la población francesa recibieron con entusiasmo la segunda proclamación de la Constitución de Cádiz ${ }^{12}$.

En Rusia la revolución española también despertó un gran interés, tanto entre los revolucionarios decembristas, como entre los contrarrevolucionarios. El gobierno del Zar Alejandro I puso en marcha una campaña de desprestigio de la revolución española, presentándola como una revuelta anárquica y sanguinaria, equiparándola a la Revolución Francesa, que actuaba como espantapájaros ideológico de la contrarrevolución. De hecho, Alejandro I se convirtió en el principal enemigo de la revolución española, encabezando las propuestas intervencionistas desde el primer momento ${ }^{13}$.

7 Ver PELOSI, Hebe: "La política exterior de España en el Trienio Constitucional", Cuadernos de Historia de España, ${ }^{\circ}$ XLIX-L (1969), pp.214-293, LI-LII (1970), pp.316-417, y LXI-LXII (1977), pp.387-443; CHURCH, Clive H.: "De 1820 a 1830: Ejércitos y violencia revolucionaria en la Europa de principios del siglo XIX", en Alberto Gil Novales (dir.): Homenaje al general Rafael de Riego. Ejército, pueblo y constitución. Siglos XIX y XX, Madrid, Trienio Anejos, 1988, pp. 327-364; SCHMIEDER, Ulrike: Prusia y el Congreso de Verona. Estudio acerca de la política de la Santa Alianza en la cuestión española, Madrid, Orto, 1998, pp.15-47; GIL NOVALES, Alberto: "España exporta la revolución. Repercusiones internacionales del Trienio Liberal", Cuadernos de Historia 16 El Trienio Liberal, Madrid, 1985, pp. 20-31.

8 Citado por WARESQUIEL, Emmanuel e YVERT, Benoît: Histoire de la Restauration, 1814-1830. Naissance de la France moderne, Paris, Perrin, 1996, p. 296. Ver PASQUIER, Étienne-Denis: Histoire de mon temps. Mémoires du chancelier Pasquier, publiés par M. le duc d'Audiffret-Pasquier, 6 vols., París, E. Plon, Nourrit et Cia imprimeurs-editeurs, 1893-1895. Ver también LAUMIER, Charles L.: Histoire de la Révolution d'Espagne en 1820, París, Imprimerie de Chaignieau fils, 1820.

9 La información oficial en los Archives du Ministère des Affaires Étrangères (AMAE), fondo "Correspondance politique. Espagne", legajos 703-725. MOLINER, Antonio: "Las Juntas durante el Trienio Liberal", Hispania, LVII, 1, no 195 (1997), pp. 147-181, ha analizado a fondo esta correspondencia.

10 Ver CASTRO MARTÍNEZ, Antonio: "Las lecturas en la prensa del Trienio de Louis Pêche, agente del gobierno francés", Aportes, no 38 (1998), pp. 27-36.

11 Archives Nationales de France (ANF), Fondo F7, Police, legajo 6.644.

12 Para la incidencia en Francia de la revolución española ver DE BERTIER DE SAUVIGNY, Guillaume: La Restauration, París, Flamarion, 1974 [1955], pp.178-196; WARESQUIEL, Emmanuel e YVERT, Benoît: op. cit., pp. 295-406; y SANCHEZ MANTERO, Rafael: Las conspiraciones liberales en Francia (18151823) y su relación con los pronunciamientos españoles, Sevilla, Universidad de Sevilla, Sevilla, 1972, pp. 209-214.

13 Ver DODOLEV, Mikhail Alekseevich: Rossiia i Ispaniia, 1808-1823 gg.: voina i revoliutsiia v Ispanii i Russko-Ispanskiie otnoxeniia, Moscou, Nauka, 1984, y "Rusia y la revolución española de 1820-1823", Cuadernos de Historia Económica de Cataluña, V (1971), pp. 118-132; FERRANDO BADÍA, Juan: "Proyección exterior de la Constitución de 1812", Ayer, no 1 (1991), pp. 207-248; y "La Constitución española de 1812 y el Congreso de Verona”, Gades, n 16 (1987), pp. 57-89. 
Inglaterra, en cambio, mantuvo en un primer momento una postura neutral. Siguió el proceso revolucionario con interés e intentó mantener los contactos, tanto con el gobierno constitucional, como con los absolutistas, con el objetivo de consolidar las buenas relaciones que había entre los dos países desde la guerra contra los franceses ${ }^{14}$. Una vez triunfó la revolución, el gobierno inglés, a través de su cónsul en Madrid, presionó para modificar la Constitución de 1812 como garantía de moderación del sistema constitucional español ${ }^{15}$. El gobierno inglés se mostró siempre más preocupado por el carácter de la revolución, que por la revolución misma, tal y como manifestaba el embajador en Londres, duque de Frías: "Miran como muy quebradizo el orden que se ha seguido hasta aquí en España. Creen que las pasiones o cualquier otra causa acarrearán tal vez desórdenes y calamidades. V.E. conoce que aquí, como en la mayor parte de los países que han pasado por las crisis revolucionarias temen mucho la efervescencia de los cuerpos legislativos nacientes, y los funestos sucesos de la revolución francesa, siempre los tienen a la vista"16.

El mes de agosto de 1820, cuando el sistema constitucional parecía consolidado, el único lugar de Europa desde donde se recibían noticias favorables era de Inglaterra. El embajador español en Londres señalaba que el gobierno anglosajón, a pesar de los interrogantes que generaba el nuevo sistema político, no mostraba preocupación por los cambios ocurridos en España: "Inglaterra pues, tiene su atención en las cosas de Italia, y muy fundadamente enemiga de la Francia y desconfiada de la Rusia, dirige sus miras a evitar la preponderancia de estas dos Naciones. No contribuye poco a esta conducta la protección que la Francia da a la emancipación de nuestras posesiones de América" ${ }^{17}$. En esta misma dirección se expresa el duque de Wellington quién, por una parte muestra su descontento por el carácter democrático del sistema constitucional español, pero por otra se niega a cualquier intervención extranjera en España y propone que sea el mismo rey, quien, "por medio de Cortes, trate de conseguir una reforma que cambie la Constitución de revolucionaria en conservadora" 18 .

Los embajadores españoles en las monarquías europeas mantenían constantemente informado al Secretario del despacho de Estado respecto de la opinión de los gobiernos sobre la evolución política de España. Debemos, pero, diferenciar entre aquellos de ideas absolutistas, que recalcaban la percepción negativa de la revolución constitucional allí donde ejercían su trabajo; y aquellos otros de ideas liberales que, sin esconder los problemas, se hacían eco de la buena acogida que había tenido la nueva promulgación de la Constitución de Cádiz. Serán estos últimos los que realizarán una ardua tarea

14 Ver GUERRERO, Ana Clara: "La política británica hacia España en el Trienio Constitucional", Espacio, Tiempo y Forma, IV (1991), pp. 215-240; WADDELL, David A. G.: "Relaciones anglo-españolas y la pacificación de América durante el Trienio Constitucional, 1820-1823", Anuario de Estudios Americanos, $\mathrm{n}^{\circ}$ 46 (1989), pp.455-486. Desde el 25 de enero y hasta el 31 de marzo de 1820, The Times informará constantemente sobre la insurrección militar y los pronunciamientos constitucionales en diversas ciudades españolas. 15 Informe del 6 de abril de 1820, reproducidos por MORENO ALONSO, Manuel: "La revolución liberal de 1820 ante la opinión pública española”, Revista de Estudios Políticos, nº 52 (1986), pp. 91-110, pp. 96-97 para la cita concreta.

16 Carta con fecha de 25 de agosto de 1820 (AHN, Estado, legajo 2.983).

17 Carta con fecha de 26 de agosto de 1820 (AHN, Estado, legajo 2.983).

18 Carta a Richelieu con fecha de 30 de marzo de 1820, reproducida en AZCARATE, Pablo de: Wellington y España, Madrid, Espasa Calpe, 1960, pp. 229-233. Ver también GIL NOVALES, Alberto: Images of Wellington and Britain in Spain after 1815, Southampton, University of Southampton, 1990. 
para hacer aceptable la nueva situación política española por parte de los gobiernos de las principales potencias europeas.

En la línea liberal debe destacarse los esfuerzos realizados por el embajador español en Prusia, Pascual Vallejo. Éste se dirigió en diversas ocasiones al monarca prusiano manifestándole que Fernando VII había aceptado la Constitución voluntariamente y que mediante un manifiesto había encabezado el cambio político para garantizar el orden y la tranquilidad pública, y que estos cambios no debían comportar ninguna modificación de "las relaciones políticas existentes entre España y Prusia"19. Vallejo justificó también la necesidad del cambio político en España para "mejorar el régimen de su gobierno para salir del abatimiento en que yacía”, así como la adopción de la Constitución de 1812 que "restablece las antiguas leyes fundamentales de la Monarquía española, y especialmente algunas de las que estaban en vigor en Aragón" 20 . El embajador español, pero, se lamentaba que la opinión del monarca y del gobierno prusiano respecto de la revolución y la constitución española seguía siendo muy negativa, alegando que "ni la nobleza ni el clero gozaban de representación directa en las Cortes" 21 .

Por su parte, el embajador español en Roma, el absolutista Antonio de Vargas, manifestaba que la proclamación de la Constitución en España no había sido bien recibida en Roma, pero que no había problema porque "este Gobierno carece absolutamente de influjo según he manifestado en otras ocasiones, respeta las deliberaciones de los demás y permanece siempre pasivo"22. No fue exactamente así, y tanto el secretario del Papa Pío VII, Consalvi, como el nuncio en España, Giacomo Giustiniani, conspiraron muy pronto para derrocar al régimen constitucional, al mismo tiempo que en Roma se creaba una congregación de cardenales encargada de analizar la política española ${ }^{23}$.

A medida que el régimen constitucional español se fue consolidando, más desconfianza y miedo generó entre las potencias europeas. A mediados de abril de 1820 , Vallejo informaba que los gobiernos prusiano y francés: "se hallaban alarmados por las últimas noticias de España, que les hacían creer reinaba en varias partes de ella una especie de anarquía" 24 . En una carta posterior se hacía eco de la opinión del secretario del despacho de Estado prusiano que se había quejado de la radicalidad de la revolución española y del exceso de democracia que contemplaba la Constitución de 1812 y apostaba por su reforma "en cual hace principalmente referencia a la $2^{\text {a }}$ Cámara que contrapese a la $1^{\text {a" }}$ y a la elaboración de una nueva ley electoral para que "haya la proporción que es justa entre los Diputados de la Península, y los de Ultramar, y se evite que los de Ultramar sean en más número que los del Continente"25. Las potencias absolutistas, pero, no se limitaron a manifestar al gobierno español su

19 Carta de Pascual Vallejo al Secretario de Estado fechada en Berlín, el 6 de abril de 1820 (AHN, Estado, legajo 2.983).

20 Carta fechada en Berlín, el 7 de abril de 1820 (AHN, Estado, legajo 2.983).

21 Carta con fecha de 7 de abril de 1820 (AHN, Estado, legajo 2.983).

22 Carta fechada en Roma el 15 de abril de 1820 (AHN, Estado, legajo 2.983).

23 Para la posición de la Santa Sede respecto de la revolución española ver RODRÍGUEZ LÓPEZ-BREA, Carlos $\mathrm{M}^{\mathrm{a}}$ : "La Santa Sede y los movimientos revolucionarios europeos de 1820. Los casos napolitano y español", Ayer, no 45 (2002), pp. 252-273.

24 Carta con fecha de 17 de abril (AHN, Estado, legajo 2.983).

25 Carta fechada en Berlín el 18 de abril de 1820 (AHN, Estado, legajo 2.983). 
opinión y a proponer reformas, sino que algunas iniciaron los contactos con los contrarrevolucionarios españoles ${ }^{26}$.

La opinión desfavorable de la mayoría de gobiernos europeos respecto de la revolución española, contrastaba, según los informes de los embajadores liberales, con la simpatía que despertaban la revolución y la constitución españolas entre los pueblos de Europa. Desde la ciudad italiana de Luca se informaba que: "habiéndose impreso en Pisa una traducción de la Constitución de la Monarquía Española, que también se vendía en Florencia, se ha prohibido y mandado suspender su venta, aunque sin haberse publicado decreto formal del Gran Duque [de la Toscana] al efecto"27. Por su parte, el embajador en Turín, Eusebio de Bardají, iba más allá:

Las noticias que recibo de todas partes acerca de la impresión que han causado los últimos acontecimientos de España me confirman más y más en la idea de que tarde o temprano el sistema constitucional y representativo será adoptado generalmente, sin que sea bastante para impedirlo la manera poco favorable con que han presentado los sucesos los gazeteros franceses del partido que V.E. no ignora, la malignidad con que desfiguran los hechos, la imprudencia con que truecan los decretos del Rey y los alborotos y discusiones que forjan cada día.

[...] Lo que digo de Italia debe aplicarse igualmente a todos los demás países de Europa, sin exceptuar aquellos donde se trabaja con el mayor empeño en sofocar las ideas que ya han nacido robusteciéndose al punto de no poder ser destruidas y aniquiladas ${ }^{28}$.

Y lo mismo pasaba en Francia, según las informaciones que publicaba el Diario Constitucional y Mercantil de Tarragona: "Todas las Cartas de Francia que hemos visto están contestes en orden al entusiasmo que han producido en aquel país las ocurrencias de España"29.

\section{La Constitución de 1812 en 1820: "la palabra, el nombre y el estandarte"}

La segunda proclamación de la Constitución de Cádiz, tuvo tanta repercusión en Europa, como su aprobación por las Cortes de Cádiz el $1812^{30}$. Los elementos democráticos de la Constitución de $1812^{31}$ la convertían en una de las más avanzadas de

26 Sirva como demostración el hecho que se interceptó en Vitoria diversa correspondencia entre ministros extranjeros y contrarrevolucionarios españoles a mediados 1820 (AHN, Estado, legajo 2.988).

27 Carta con fecha de 17 de abril de 1820 (AHN, Estado, legajo 2.983).

28 Carta con fecha de 2 de mayo de 1820 (AHN, Estado, legajo 2.983).

29 Diario Constitucional y Mercantil de la ciudad de Tarragona, $\mathrm{n}^{\circ} 2$ de 16 de abril, y n⿳ 20 de 3 de mayo de 1820 , pp.5 y 80.

30 FERRANDO BADÍA, Juan: "Proyección exterior de la Constitución de 1812", Ayer, no 1 (1991), pp. 207-248; CASTELLS, Irene: "La constitución gaditana de 1812 y su proyección en los movimientos liberales europeos del primer tercio del siglo XIX", Trocadero, no 1 (1989), pp. 117-132; FERNÁNDEZ SARASOLA, Ignacio: "La Constitución española de 1812 y su proyección europea e iberoamericana", Fundamentos. Cuadernos monográficos de Teoría del estado, Derecho Público e Historia Constitucional, no 2 (2000), pp. 359-466. Ver también FRANCESCO, Antonio de: "La Constitución de Cádiz en Nápoles" y DIPPEL, Horst: "La significación de la constitución española de 1812 para los nacientes liberalismo y constitucionalismo ale-

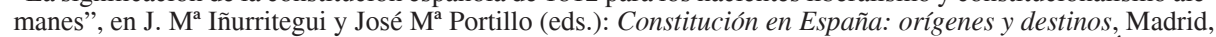
Centro de Estudios políticos y constitucionales, 1998, pp. 273-286 y 287-308; FERRANDO BADÍA, Juan: La constitución española de 1812 en los comienzos del Risorgimento, Roma-Madrid, CSIC, 1959.

31 Para la Constitución de 1812 ver VARELA, Joaquín: La teoría del estado en los orígenes del constitucionalismo hispánico (Las Cortes de Cádiz), Madrid, Centro de Estudios Constitucionales, 1983, "La Constitución de Cádiz y el liberalismo español del siglo XIX”, Revista de las Cortes Generales, no 10 (1987), 
Europa durante el primer tercio del siglo XIX y por ello, tal y como se señalaba desde las páginas de la Diana constitucional de Reus, contó también con muchos enemigos, tanto dentro como fuera del país: "no nos extrañemos de que ella sea el blanco contra el cual esta aislada casta de hombres que no reconoce más compatricios que a los oligárquicos, desfogue toda su rabia y furor" ${ }^{32}$. Pero, al mismo tiempo, como escribió el conde italiano César Balbo, se convirtió en "la palabra, el nombre, el estandarte, en torno al cual se reunían los liberales"33.

La polémica sobre la Constitución de 1812 que se había vivido con intensidad durante la época las Cortes de Cádiz, se vivió de nuevo durante el Trienio ${ }^{34}$. El debate se extendió por toda Europa y los politólogos ingleses, como Jeremy Bentham, fueron los primeros en criticar el democratismo de la Constitución de 1812. Críticas a las que se sumaron los liberales moderados franceses, como Benjamin Constant o Dominique Dufour Pradt, que reclamaron las dos cámaras ${ }^{35}$. Naturalmente, los ultras europeos no querían saber nada de la Constitución española, como podemos comprobar en los escritos de François René Chateaubriand o de Karl Ludwig von Haller $^{36}$.

Pero también es cierto que la Constitución española de 1812 tuvo muchos partidarios en la Europa del primer tercio del siglo XIX, sobre todo durante la década de los veinte, y una muestra de ello es que se publicó en inglés, francés, portugués, italiano y alemán ${ }^{37}$. Sirva también de ejemplo que a finales marzo de 1821 y desde la ciudad

pp. 27-109, y "La monarquía imposible: la Constitución de Cádiz durante el Trienio", Anuario de Historia del Derecho Español, t. LXVI (1996), pp. 653-687; CANO, José (ed.): Materiales para el estudio de la Constitución de 1812, Madrid, Tecnos, 1989; y ARTOLA, Miguel (ed.), "Las Cortes de Cádiz", Ayer, nº 1 (1991).

32 "Variedades", firmado por El amigo de la Verdad, Diana constitucional, política y mercantil de Reus, $\mathrm{n}^{\circ}$ 64 , de 27 de agosto de 1822 , p.4.

33 Citado por FERRANDO BADÍA, José: La constitución española ... p. 78. El entusiasmo de los liberales europeos por la Constitución española de 1812 queda perfectamente reflejado en el texto del abogado romano refugiado en España FIORILY, Bartolomé: La mejor Constitución posible para todas las naciones. El texto fue presentado a las Cortes por el diputado Calatrava (DSC, 1821, t. II, p.1.551, sesión 73, de 11 de mayo). 34 Ver MIRAFLORES, Marqués de [Manuel Pando Fernández de Pinedo]: Apuntes histórico para escribir la historia de la revolución de España desde el año de 1820 hasta 1823, Londres, Ricardo Taylor, 1834; QUINTANA, Manuel José: Cartas a Lord Holland sobre los sucesos políticos de España en la segunda época constitucional. Obras Completas, Madrid, Atlas-BAE, 1946 [Madrid, 1853]; MORENO ALONSO, Manuel: "Principios políticos y razones personales para la reforma del estado en España (1805-1840) (De la correspondencia inédita de M.J. Quintana con Lord Holland)", Revista de Estudios Políticos, no 70 (1990), pp. 289-338.

35 BENTHAM, Jérémie: Essais de Jérémie Bentham sur la situation politiques de l'Espagne, sur la Constitution et sur le nouveau Code espagnol, sur la Constitution du Portugal, Paris, Brissot-Thivars, 1823; PRADT, Abate de: La Revolución actual de España y sus consecuencias, Valencia, J.F.G, 1820 [Paris, 1820]; DUVERGIER De HAURANNE, Maurize: Ojeada sobre España, Londres, 1825 [Paris, 1824]; DENIS, Jean compte de Lanjuinais: "Vues politiques sur les changements à faire à la Constitution d'Espagne afin de la consolider, spécialement dans le Royaume des Deux-Siciles (1821)", V. LANJUINAIS (ed.): Ses ouvres, avec une notice biographique, Paris, Dondey-Dupré, 1832.

36 CHATEAUBRIAND, René: El Congreso de Verona. Guerra de España. Negociaciones colonias Españolas, 2 vol., Madrid, Imprenta de Fuentenebró, 1839; y HALLER, Karl Ludwig von: Análisis de la Constitución española, Madrid, Imprenta de Collado, 1823 [1814].

37 Sirvan de ejemplo la Constitution politique de la monarchie espagnole: promulguée a Cadix le 19 de mars 1812 traduite de L'Espagnol par Aimé Duvergier, París, Imprimerie de P.-F. Dupont, 1820; la Costituzione politica della Monarchia Spagnuola: tradotta per ordine del Governo, Nápoles, Edizione uffiziale, 1820; y Die spanische Constitution der Cortes und die provisorische Constitution der Bereinigten provinzen von Sudamerika: aus deu Urkunden ubersetz mit historich-statistischen Einleitungen, Leipzig, F .U. Brockhaus, 1820. El 1814 se había traducido al italiano y al francés y en 1825 se tradujo al ruso. También se publicaron gravados con algunos actos constitucionales, como por ejemplo el juramento constitucional de la guardia de 
francesa de Grenoble, se hizo correr la voz que Luis XVIII había abdicado la corona en el duque de Orleans, quien habría proclamado la Constitución española. La noticia provocó un gran revuelo cuando unos 600 ciudadanos se manifestaron con la bandera tricolor y se declaró el estado de sitio $^{38}$. Como señalaba el reaccionario vizconde de Martignac el miedo se apoderó de los soberanos absolutistas: "Los movimientos sediciosos se manifestaron en Grenoble y Lyon, y una fermentación sorda, pero activa, que era un síntoma de que habían aprendido a conocer, parecía amenazar el reino con una nueva sacudida" 39 .

\section{La reacción del absolutismo europeo}

La política internacional de la Junta Provisional y del primer gobierno constitucional español fueron muy moderadas, tal y como podemos comprobar en la Memoria presentada a las Cortes por el secretario del despacho de Estado, Evaristo Pérez de Castro $^{40}$. Una moderación que contrastaba con la beligerancia creciente de las potencias absolutistas europeas.

A la Junta Provisional de gobierno tan solo le preocupó la frontera francesa ya que, como refleja la correspondencia diplomática de los meses de abril a junio de 1820, se temía que la progresiva concentración de tropas francesas acabara con una invasión ${ }^{41}$. La Junta Provisional realizó numerosas gestiones ante el embajador francés en Madrid para que su gobierno retirase las tropas de la frontera, pero este siempre desmintió que se hubieran reforzado dichas tropas. Si bien era cierto que en aquel momento las autoridades francesas no tenían ninguna intención de invadir España, también lo era que temían el "contagio revolucionario", ya que según se informaba desde el otro lado de la frontera "el espíritu público de los departamentos fronterizos de Francia es favorable al sistema actual de España"42. La Junta Provisional no adoptó ninguna medida enérgica contra el gobierno francés, al contrario, intentó enmascarar sistemáticamente los informes del Jefe político de Cataluña sobre la presencia de dichas tropas en la frontera, hasta el punto de dar la razón a las autoridades francesas y afirmar que "se sabe son infundados los rumores sobre reunión de tropas en la frontera francesa"43.

A partir del mes de septiembre, la correspondencia diplomática del gobierno español refleja una gran preocupación por el impacto europeo de las revoluciones en

\footnotetext{
Madrid: Serment de la garnison de Madrid a la constitution des Cortès: Le 10 Mars 1820, París, Basset. M. d'Estampes rue S.t Jacques $\mathrm{N}^{\circ}$ 64, 1820.

38 Ver la noticia publicada en una hoja suelta Noticias Estraordinarias, Barcelona, 28 de marzo de 1821 (un ejemplar en el AMAE "Correspondance comerciale. Barcelone”, t.24, f.211).

39 Ver MARTIGNAC, Vicomte de [J.B. GAYE]: Essais historique sur la révolution d'Espagne et sur l'interventión de 1823, París, A. Pinard, 1832 [traducido al castellano el año 1823 con el título de La España y sus revoluciones], pp.284-286.

40 "Memoria leída a las Cortes por el Sr. Secretario del despacho de Estado en la Sesión de 11 de Julio de 1820 " (AHN, Estado, legajo 2.983).

41 AHN, Estado, legajo 3.032-2. Ver también los informes del Jefe político y del Capitán general de Catalunya al Secretario de Gobernación (8 de abril de 1820) y de este con el Secretario de Estado y de la Guerra (8 y 9 de abril de 1820). Ver también la carta del barón Pasquier de 19 de abril de 1820 (Archivo del Congreso de los Diputados (ACD). Papeles Reservados Fernando VII (PRFVII), t.35, ff.127 y 199).

42 Oficio del Secretario de la Guerra a la Junta provisional, reproduciendo una carta del teniente coronel José Cortinies desde Perpinyá con fecha de 15 de abril de 1820 (ACD, PRFVII, t.35, ff. 175 y 186, y t.38, ff. 272-275).

43 Oficio de la Secretaria de Estado a la Junta Provisional con fecha de 29 de abril de 1820 (ACD, PRFVII, t.35, f.229).
} 
Nápoles y Sicilia ( 2 y 3 de julio de 1820$)^{44}$ y en Portugal (24 agosto de 1820$)^{45}$ y por las repercusiones que podía tener para España. Una preocupación muy real como podemos comprobar en la celebración de la conferencia de Troppau el mes de octubre de 1820 y la Laybach el mes de enero de 1821.

Era evidente que en la revolución portuguesa había habido influencia española, tal y como señala el nuncio en Lisboa, Cherubini: "fu opera dell'influsso Spagnuolo, di Fratelli, e di alcuni Ufficiali" ${ }^{46}$. Precisamente en este contexto reapareció la propuesta del iberismo constitucional, de la mejora de las relaciones hispano-portuguesas y de una Alianza Ibérica el año $1821^{47}$. A pesar de que esta no cuajó finalmente, en aquella coyuntura era una posibilidad real, tal y como señala el nuncio en Lisboa: "si è parlato moltissimo della unione di questo Regno con la Spagna in caso di ostilità dei Sovrani uniti in Läybach"48.

A partir de finales de invierno y principios de primavera de 1821 empezó a hablarse seriamente de una posible invasión de España por parte de los ejércitos de la Santa Alianza. El gobierno español optó por seguir manteniendo una postura “perfectamente neutral" respecto del régimen constitucional de Nápoles, dejando que las potencias absolutistas actuasen libremente para acabar con él, siguiendo los acuerdos del congreso de Troppau ${ }^{49}$. El gobierno español pensaba que desentendiéndose de las otras revoluciones que habían seguido sus pasos conseguiría salvar su régimen constitucional. Pero esta actitud permitió a las potencias absolutistas apagar los "incendios revolucionarios"

44 Ver PEPE, Guillermo: Memoria relativa a los sucesos de Nápoles en los años 1820 y 1821, Madrid, Imprenta de D. Miguel de Burgos 1822; LEPRE, Aurelio: La rivoluzione napoletana del 1820-1821, Roma, Riuniti, 1967; SPINI, Georgio: "Mito e realtà della Spagna nelle rivoluzioni italiane del 1820-21", en G. Spini (ed.): Incontri europei e americani col Risorgimento, Roma, Perella, 1950, pp. 37-196; CANDELORO, Giorgio: "L'ondata rivoluzionaria del 1820-21", Storia dell'Italia Moderna, Vol II Dalla restaurazione alla rivoluzione nazionale, 1815-1846, Roma, Feltrinelli, 1978, pp. 74-135; FRANCESCO, Lemmi y otros: $L a$ rivoluzione piemontese dell'anno 1821, Turín, Fratelli Bocca, 1923; CANDIDO, Salvatore: "La revolución de Cádiz de enero de 1820 y sus repercusiones en Italia, en los reinos de Nápoles y de Cerdeña (1820-1821)" y SCOTTI DOUGLAS, Vittorio: "La constitución de Cádiz y las revoluciones italianas en Turín y Nápoles de 1820 y 1821", en A. Gil Novales (ed.), La Revolución Liberal, Ediciones del Orto, Madrid, 2001, pp. 251255 y 257-262; BISTARELLI, Agostino: "El espejo español: la doble mirada del liberalismo revolucionario italiano en los inicios del siglo XIX", en R. Robledo, I. Castells y M ${ }^{\mathrm{a}} \mathrm{C}$. Romeo (eds.): Orígenes del Liberalismo: Universidad, política, economía, Salamanca, Universidad de Salamanca, 2003; BUTRÓN, Gonzalo: "La proyección europea del modelo revolucionario español: el mito de 1808 en la revolución piamontesa de 1821", en A. Moliner (ed.): Ocupació i resistència a la guerra del Francès, Barcelona, Museu d'Història de Catalunya, 2005, pp.1.029-1.042; BONINI, Francesc: "Au delà de Cádiz. Réformes de la Constitution de 1812 en Italie" y CORCIULO, Maria Sofia: "La Revolución napolitana de 1820-1821 en el origen del Resurgimiento italiano", en Diana Repeto (ed.): Las Cortes de Cádiz y la Historia parlamentaria, Cádiz, Universidad de Cádiz, 2012, pp. 231-241 y 243-251.

45 Ver NOBRE VARGUES, Isabel: "A Revoluçâo de 1820. Notas para o estudo do liberalismo português e da sua correlaçâo peninsular", Historia Social, no 36-37 (1986), pp. 203-210, y "La Revolución de 1820. Notas para el estudio del liberalismo portugués y de su correlación pensinsular”, Siglo XIX, nº 3 (México, 1987), pp. 173-186; TENGARRINHA, Jose: "Os movimentos liberais em Espanha vistos do Portugal absolutista, 1810-1820 (a través dos relatos de espiöes e informadores)", Revista de Facultade de Letras de Lisboa, $\mathrm{n}^{\circ}$ 16-17 (1994), pp. 51-74; y TOMÁS, Manuel Fernando: A revoluçâo de 1820, Lisboa, Seara Nova, 1974. 46 Despacho cifrado el 20 de septiembre de 1820 y dirigido al Secretario de Estado de la Santa Sede (reproducido por DÍAZ DE CERIO, F., Informes... vol. II, p. 22).

47 CASTELLS, Irene: "Los orígenes del iberismo (1815-1832)", en J. Fontana (dir.), Historia i projecte social. Reconeixement a una trajectòria, Barcelona, Crítica, 2004, pp. 1.033-1.046; y EIRAS ROEL, Antonio: "La política hispano-portuguesa en el trienio constitucional", Hispania, XXIII, no 91 (1963), pp. 401-454. 48 Despacho $n^{\circ} 332$ de 24 de marzo de 1821 (reproducido por DÍAZ DE CERIO, F., Informes... vol. II, p. 25).

49 "Memoria leída a las Cortes por el Sr. Secretario del despacho de Estado en la Sesión de 11 de Julio de $1820 "$ (AHN, Estado, legajo 2.983). 
uno tras otro, sin tener que afrontarlos conjuntamente. Los sistemas constitucionales de Nápoles y Sicilia fueron aplastados por las tropas austriacas el 23 de marzo de 1821; y el del Piamonte el 10 de abril de 1821, provocando una fuerte oleada de emigración política hacia España. El posicionamiento del gobierno liberal moderado español no reportará ningún beneficio a la España constitucional. Al contrario, a finales de enero de 1821, el embajador español en París, marqués de Santa Cruz, manifestaba que el gobierno francés: "Había comisionado algunos de sus Generales para que formen un Plan de Campaña contra España"

A partir del verano de 1820 fueron cada vez más frecuentes las noticias sobre la actividad de los contrarrevolucionarios españoles en Francia en la correspondencia diplomática $^{51}$. A primeros de febrero de 1821 el cónsul español en Bayona, Juan Hernández, manifestaba haber descubierto un plan conspirativo que tenia su centro en esta ciudad francesa, que se agrupaba alrededor de la sociedad "Los Amigos del Orden" y que su objetivo era "destruir la Constitución y restablecer el Antiguo Gobierno" 52 . Una actividad que no podía desarrollarse sin el beneplácito del gobierno francés, tal y como denunciaba un comerciante de Perpiñán, "en cuyos hechos presumo que mi gobierno tiene alguna influencia" 53 .

De hecho, los contrarrevolucionarios españoles confiaron desde el primer momento en la ayuda de los gobiernos absolutistas europeos para acabar con el sistema constitucional, tal y como informaba el cónsul de Bayona: "fundan su plan y sus esperanzas en las que tienen de que el Gobierno Francés y los Soberanos y Gabinetes de Europa reunidos en Laybach tomarán parte en el restablecimiento del antiguo sistema de España"54. Finalmente, será en el Congreso de Verona donde se decidirá la invasión de España y que acabará protagonizando el ejército francés de los Cien Mil Hijos de San Luis, para acabar con el régimen constitucional y restaurar el absolutismo (primavera de 1823).

\section{EL IMPACTO EN AMÉRICA}

\section{Una incomprensión mutua}

El impacto de la segunda proclamación de la Constitución de Cádiz en América, fue mucho menor que en Europa. Aún así, se produjeron diversas reacciones. En la Habana, cuando llegaron las noticias de la publicación de la Constitución en España, el día 16 de abril de 1820, los vecinos de la ciudad y su guarnición juraron la Constitución, pero sus jefes se negaron a hacerlo, por ello los oficiales y soldados del batallón ligero de Tarragona acuartelado en dicha ciudad, se pronunciaron contra sus jefes a los que acusaban de absolutistas ${ }^{55}$. En la Ciudad de Toluca (México) se juró la Constitución de

50 Carta enviada desde París el 28 de enero de 1821 por el marqués de Santa Cruz al Secretario de Estado Evaristo Pérez de Castro (AHN, Estado, legajo 3.032-1).

51 Ver las cartas del cónsul de Bayona de Carta de 25 de agosto y 12 de noviembre de 1820 (AHN, Estado, legajo 5.228). Para la actividad contrarrevolucionaria desde Francia ver ARNABAT, Ramon: Visca el Rei la Religió. La primera guerra civil de la Catalunya contemporània (1820-1823), Lleida, Pagès, 2006, pp.21-72. 52 Carta de Juan Hernández fechada en Bayona el 1 de febrero de 1821 dirigida al Secretario de Estado (AHN, Estado, legajo 3.032-1).

53 Informe de un comerciante de Perpinyà al vicecónsul de esta ciudad de 4 de febrero de 1821 (AHN, Estado, legajo 5.228).

54 Carta con fecha de 16 de febrero de 1821 (AHN, Estado, legajo 5.228).

55 Archivo Histórico Nacional. Sección Estado, legajo 107, expediente 22. Ver POESÍAS que para el día en que la ciudad de México juró la Constitución de la Monarquía española disponía Don José María Villaseñor 
1812 el 11 de junio de $1820^{56}$. En la ciudad de México se fundó en 1820 una cátedra de exposición de la Constitución política de la monarquía española en la Universidad Nacional y Pontificia y el 18 de julio de 1820 el arzobispo de México, Pedro José de Fonte, hizo jurar la Constitución al clero secular y regular de su diócesis ${ }^{57}$. En la misma ciudad se reimprimió la Cartilla o catecismo del ciudadano constitucional ${ }^{58}$. En México y en Veracruz se reimprimió el texto El Amante de la Constitución publicado originariamente en Madrid ${ }^{59}$. También en México se publicó en 1820 la Representación de la diputación americana a las Cortes de España en $1^{\circ}$ de agosto de 1811 , aduciendo que "esta representación, en que tan al vivo se manifiestan los verdaderos sentimientos de los Americanos, no se publicó en los Diarios de Cortes; por lo que nos pareció conveniente vea la luz pública en esta Capital para no privar a sus habitantes de un documento tan interesante" ${ }^{\circ 0}$.

En cualquier caso, en 1820 la capacidad de maniobra de la monarquía española respecto de América era ya muy reducida. Durante las Cortes de Cádiz habían fracasado los intentos de construir una nación que abarcara a los "españoles de ambos hemisferios" ${ }^{61} \mathrm{y}$, posteriormente, los americanos fueron agraviados por la política de la restauración absolutista, reforzando los procesos independentistas ${ }^{62}$. Tal y como reco-

Cervantes, México, Imprenta de Don Juan Bautista de Arizpe, 1820.

56 QUINTANA ROO, Andrés: La libertad y la tiranía: composición alegórica del juramento de la Constitución política de la Monarquía Española solemnizado en la ciudad de Toluca a 11 de junio de 1820, México, Imprenta de D. Juan Bautista Arizpe, 1820.

57 [Fernández de San Salvador, Agustín Pomposo]: Al libertador del mundo, al pacificador y padre beneficentisimo de la Nueva España, el Exmo. Sr. D. Juan Ruiz de Apodaca y Eliza ... dedicó esta efusión de la verdad ... y el agradecimiento el Dr. D. Agustín Pomposo Fernández de San Salvador con motivo de la visita que S. E. ... hizo a la Nacional y Pontificia Universidad de Méjico el 28 de diciembre de 1820, en la cual se hizo la solemne apertura de la cátedra de esposición de la Constitución política de la Monarquía, México, Oficina de Ontiveros, 1820. [DE FONTE y HERNÁNDEZ, Pedro]: Don Pedro José de Fonte Arzobispo de Méjico al respetable Clero Secular y Regular de esta Diócesis: Hago saber: Que habiendo ordenado D. Fernando Séptimo, el juramento y observancia de la Constitución política de la Monarquía firmada en Cádiz. de mil ochocientos doce, México, 1820. Sobre el arzobispo De Fonte ver NAVARRO, Luis: "El rey y la grey. El arzobispo Fonte en la independencia de México", Revista Hispanoamericana, n 1 (2011), pp.1-24 [revista digital: http://revista.raha.es/LuisNavarro.pdf].

58 CARTILLA o catecismo del ciudadano constitucional, México, Imprenta de Ontiveros, 1820 [reimpresión].

59 [R.A.]: El Amante de la Constitución, Madrid, 1820 (reimpreso en Veracruz, 1820 y México: Imprenta de Ontiveros, 1820].

60 REPRESENTACIÓN de la diputación americana a las Cortes de España: en $1^{o}$ de agosto de 1811: con notas del editor inglés [Londres en la imprenta de Schulze y Dean], México, reimpreso en la oficina de D. Alexandro Valdés, 1820.

61 BUTRÓN PRIDA, Gonzalo (ed.): Las Españas y las Américas: los españoles de ambos hemisferios ante la crisis de la independencia, Cádiz, Universidad de Cádiz, 2012; CHUST, Manuel: La cuestión nacional americana en las Cortes de Cádiz (1810-1814), València, Centro Francisco Tomás y Valiente UNED, 1999; y BREÑA, Roberto: "El primer liberalismo español y su proyección hispanoamericana", en I. Jaksic y E. Posada (eds.): Liberalismo y poder. Latinoamérica en el siglo XIX, Santiago de Chile, Fondo de Cultura Económica, 2011, pp. 63-88.

62 Bethell, Leslie (ed): Historia de América Latina, vol. 5. La independencia y vol.6. América Latina independiente, 1820-1870, Barcelona, Crítica, 1990; GUERRA, François-Xavier (dir): Revoluciones Hispánicas. Independencias americanas y liberalismo español, Madrid, Universidad Complutense, 1995; Manuel CHUST (ed.): Revoluciones y revolucionarios en el Mundo Hispánico, Castellón, Universitat Jaume I, 2000 y Las independencias iberoamericanas en su laberinto. Controversias, cuestiones, interpretaciones, València, Universitat de Valéncia, 2010; LYNCH, John: Las revoluciones hispanoamericanas, 1808-1826, Barcelona, Ariel, 1976 y España y la independencia de América, México, FCE, 1986; ANNA, Timothy E.: España y la independencia de América, México, FCE, 1986; PÉREZ, Joseph y ALBEROLA, Armando (ed.): España y América entre la Ilustración y el Liberalismo, Alacant, Institut de Cultura Juan Gil-Albert, 1993; y Annino, Antonio y Guerra, François-Xavier: Modernidad e Independencia. Ensayos sobre las revoluciones 
nocían el mes de mayo de 1820 los editores de la madrileña Miscelánea de comercio, artes y literatura: "Gran parte de nuestras posesiones americanas está emancipada, de hecho, y en cuanto al derecho, todas ellas tienen para exigir que se les saque de la abyección y del abatimiento a que por tres siglos han estado condenadas. La rebelión por causa de Injusticia calificada es de derecho natural, y por consiguiente ningún crimen se puede hacer de ella a los Americanos, a los cuales se debe por el contrario la reparación de los agravios de que se quejan, y la participación completa a los beneficios de nuestro Nuevo sistema" $"$.

Ante esta situación, la Junta provisional limitó a 30 los diputados suplentes que debían representar a Ultramar en las nuevas Cortes, una tercera parte de los que habían asistido a las Cortes de Cádiz, lo cual fue considerado un nuevo agravio y originó fuertes críticas al otro lado del Atlántico ${ }^{64}$. Unas críticas que se produjeron también en el interior peninsular por parte de los nacidos en América y que habían sido convocados para elegir a los citados suplentes los días 28 y 29 de mayo de $1820^{65}$. Esta cuestión avivó el debate sobre el futuro de las antiguas colonias americanas y en el cual participaron diversas voces desde el continente americano, como, por ejemplo, los anónimos J.V.G. con sus Reflexiones importantes; J.M.D.M. con su crítica al anterior Borrones y Verdades $^{66}$. O los diversos escritos americanos que apostaban abiertamente por la independencia, como los de Manuel de la Bárcena o los anónimos A de R y A.J.F. ${ }^{67}$.

Aunque también hubo quienes defendieron la "unidad con constitución" y apostaron por el diálogo: "dichosamente ha llegado el tiempo de la justicia: así, americanos, expongamos nuestras quejas y defendamos nuestros derechos con moderación y

hispánicas, Madrid, MAPFRE, 1992. Una visión muy diferente en IZARD, Miquel: "Sin fe, sin ley y sin caudillo. Cambio cultural, liberalismo e insurgencias populares", Siglo XIX, no 3 (México, 1987), pp.113-131; y Guerra Vilaboy, Sergio: Jugar con fuego. Guerra social y utopía en la independencia de América Latina, Casa de las Américas, La Habana, 2010.

63 Miscelánea de comercio, artes y literatura, $\mathrm{n}^{\circ} 79$ de 1 de mayo de 1820, p.1.

64 EXPOSICIÓN al rey de algunos diputados de América pidiendo mayor representación, Madrid, 9 de abril de 1820, publicada en el Suplemento del 9 de abril de 1820 de la Miscelánea de comercio, artes y literatura., $\mathrm{n}^{\mathrm{o}} 72$ de 7 de abril de 1820, pp.1-2.

65 MANIFIESTO de los americanos que residen en Madrid a las naciones de la Europa y principalmente a la de España, demostrando las razones legales que tienen para no concurrir el día 28 de mayo a elegir diputados que representen a los pueblos ultramarinos donde nacieron, Madrid, Impresor de Vega y Cia, 1820; Manuel de VIDAURRE: Manifiesto sobre la nulidad de las elecciones que a nombre de los países ultramarinos se practicaron en Madrid por algunos americanos los días 28 y 29 de mayo de 1820, Madrid, Impresor de Vega y Cia, 1820. Ver BROSETA, Salvador: "La representación de la Diputación de Ultramar en las Cortes del Trienio Liberal", y CHUST, Manuel: "América en el proceso revolucionario burgués español”, en A. Gil Novales (ed.), La Revolución Liberal, Madrid, Ediciones del Orto, 2001, pp. 391-400 y 503-516. Hay un interesante análisis sobre la independencia de las colonias españolas en América realizado por Karl MARX, "Bolívar y Ponte" publicado en The New American Cyclopaedia, vol. 3, 1858, editado y traducido por RIBAS, Pedro: Karl Marx y Friedrich Engels. Escritos sobre España. Extractos de 1854, Madrid, Trotta, 1998, pp. 211-224.

66 J.V.G.: Reflexiones importantes al gobierno constitucional de América, México, Imprenta de D.J.M. Benavente y socios, 1820; J. M. D. M.: Borrones y verdades y cuenta con lo que se dice: impugnación de algunas proposiciones del impreso $n^{o}$ I. titulado Reflexiones importantes al gobierno constitucional de América por su autor el reflexivo J. V. G., México, Imprenta de Mariano de Zuñiga y Ontiveros, 1820. Ver también REFLEXIONES de un americano en vista del dictamen de la Junta consultiva sobre la representación supletoria de los españoles de ultramar, Madrid, Imprenta de la Calle de la Greda, 1820.

67 BÁRCENA, Manuel: Manifiesto al Mundo. La justicia y la necesidad de la independencia de la Nueva España, Puebla, Imprenta liberal de Moreno hermanos, 1821; A.J.F.: Ventajas de la independencia, México, Imprenta de Mariano Ontiveros, 1821; y A. de R.: La necesidad de la independencia demostrada por un joven americano, México, Oficina de los ciudadanos militares D. Joaquín y D. Bernardo de Miramón, [1821?]. 
decencia" ${ }^{68}$. Cabe destacar el trabajo explicativo en esta dirección realizado por Santiago Jonama en su réplica al abate de Pradt ${ }^{69}$.

Los comerciantes españoles esperaban que con la proclamación de la Constitución se frenara el proceso independentista americano y se fortaleciera el comercio entre los dos lados del Atlántico. Así lo manifestaba Josep Brufau, corresponsal de la importante casa comercial Cortadellas: "[el comercio] probablemente tomará vigor si los americanos disidentes a imitación de algunas provincias que han jurado con entusiasmo la Constitución, vuelven a unirse a la Matriz como muchos esperan"70. Una esperanza que compartían con los constitucionales "esta ley fundamental va a estrechar de nuevo a los Españoles de América y Europa, transformándolos en una sola e inmensa familia"71. La dependencia económica de la metrópoli española respecto de los ingresos procedentes de América era muy grande y dificultaba la aplicación de los principios civiles y políticos de la Constitución de 1812. A pesar de ello hubo algunos intentos ${ }^{72}$.

Pero había otros intereses en juego, además de los de la monarquía española y de los de los propios habitantes de las viejas colonias americanas. Inglaterra, por ejemplo, era uno de los países más interesados en estas colonias, en competencia directa con Francia y los Estados Unidos, lo cual explica en parte la postura británica respecto de la revolución española y que ya hemos comentado ${ }^{73}$. Por su parte, los Estados Unidos no pensaban dejar pasar la oportunidad de aumentar su influencia en las colonias españolas: "El partido que conviene a los Estados Unidos está tomado ya; es fuerza que reconozcan la independencia de las nuevas repúblicas y de todas las provincias de España revolucionadas, uniéndose a ellas con los lazos más estrechos. Es tiempo de proclamar altamente que la causa de las Américas españolas es la causa de toda la América separada de lo restante del mundo""74.

68 PEREZ DE AGUAYO, Manuel: Manifiesto a la América española, o Contestación al Manifiesto del Licenciado Don Juan de Dios Cañedo a la Nación Española, Madrid, Imprenta Nacional, 1820, en el cual se defiende la actuación de la Junta provisional. Ver también F.F.F.: Carta de un Constitucional de Méjico a otro de la Habana, México, reimpresa en la oficina de D. Alejandro Valdés, 1820.

69 JONAMA, Santiago: Reflexiones sobre el estado actual de la América, o Cartas al Abate de Pradt escritas en francés por un natural de la América del Sur; y traducidas al castellano por D. Antonio de Frutos Tejero, Madrid, Imprenta de Burgos, 1820.

70 Carta a Francesc Raval de Tamarite fechada el 27 de septiembre de 1820. Arxiu Històric de Tarragona (AHT). "Companyia de Calaf. Família Cortadellas", correspondencia "Cartas recibidas. 1820", vol.CA-47, f.151.

71 Impreso público Catalanes firmado por "Los Patriotas" y fechado el 10 de marzo de 1820 (Arxiu Històric del Baix Camp. Fons Municipal de Reus. Legajo 2.6.4.6).

72 Ver IDEAS de un nuevo reglamento y arancel general que puede gobernar, para la recaudación de los derechos nacionales de todas las Aduanas de la Monarquía española, La Habana, D. Dimás Cortés Díaz de Castro, 1820. Para una visión general ver FONTANA, Josep, La quiebra de la monarquia absoluta, 18141820, Crítica, Barcelona, 2002.

73 Ver MONARCHICAL projects or a Plan to place a Bourbon king on the throne of Buenos Ayres, in opposition to British interest...: with preliminary remarks... derived from authentic sources, London, W. Glindon, 1820.

74 Carta a Washington el 12 de marzo, publicada en el The Courier, y reproducida en el Diario constitucional, político y mercantil de Barcelona, $\mathrm{n}^{\circ} 63$, de 14 de mayo de 1820, pp.1-2. Ver AYALA PÉREZ, José A.: "Las relaciones diplomáticas entre España y Estados Unidos durante el Trienio Liberal (1820-1823)", Anales de la Universidad de Murcia. Filosofía y Letras, 36, 1-2 (1977-1978), pp. 237-254; TUCKER, Norman P.: Americans in Spain. Patriots, expatriates and the early american hispanists, Boston, The Athenaeum, 1980; y SÁNCHEZ MANTERO, Rafael: "Viajeros y diplomáticos en el reinado de Fernando VII. El descubrimiento de España por los americanos", Ayer, no 41 (2001), pp.141-160. 


\section{Los constitucionales españoles y América}

Durante mucho tiempo se ha dado por hecho que los constitucionales españoles del Trienio no se preocuparon por lo que pasaba en América ${ }^{75}$. En cambio, los estudios más recientes demuestran que había un gran interés por el tema americano"76. Fue Alberto Gil Novales quien planteó primero esta temática cuestionando la versión "clásica" del desinterés, y afirmando que, a pesar de la distancia informativa (unos dos meses), se recibía en España abundante información sobre lo que pasaba en América y que esta información llegaba a una parte de la población mediante libros y artículos de prensa ${ }^{77}$. Además, Gil Novales afirma que en el debate sobre este tema la posición mayoritaria entre el liberalismo español era la de mantener la unidad con igualdad, siguiendo lo que marcaba la Constitución de Cádiz, tal y como expresó claramente Álvaro Flórez de Estrada $^{78}$ frente a la concepción de unidad sin igualdad que defendían los absolutistas. Aunque también hubo algunos constitucionales españoles que aceptaban la independencia de les colonias, por ejemplo los diputados José Moreno Guerra y Juan Romero Alpuente, representantes del liberalismo exaltado ${ }^{79}$.

Una de las primeras medidas de las nuevas Cortes, el 19 de julio de 1820, fue la publicación de los textos aprobados por las Cortes ordinarias y extraordinarias de Cádiz

\footnotetext{
75 Ver por ejemplo FERNÁNDEZ ALMAGRO, Melchor: La emancipación de América y su reflejo en la conciencia española, Madrid, Instituto de Estudios Políticos, 1957 (1944); DELGADO, Jaime: La independencia de América en la prensa española, Madrid, SPH, 1949; y ENCISO, Luis M.: La opinión española y la independencia hispanoamericana, 1819-1820, Valladolid, Universidad de Valladolid, 1967.

76 Ver MARTÍNEZ DE LAS HERAS, Agustín: "La ideología de la prensa del Trienio en relación con la independencia hispanoamericana", en A. Gil Novales (ed.): Ciencia e independencia política, Madrid, Ediciones del Orto, 1996, pp. 7-53; ZEUSKE, Michael: "Política colonial, reforma y revolución: Cuba y la independencia de la Costa Firme 1808-1821" Trienio. Ilustración y LIberalismo, $\mathrm{n}^{\circ} 24$ (1994), pp. 63-96; PÉREZ, Joseph: "Poble i nació en la crisi revolucionària d'Hispanoamèrica (1808-1830)", en Perspectives entorn de la Revolució Francesa, Barcelona, L'Avenç, 1988, pp. 37-51; SALVATORI, Candido: "La revolución de Cádiz y la implicación hispanoamericana en las vicisitudes constitucionales de España en los despachos de los enviados del Rey de Cerdeña en la Corte de Madrid (1820-1822)", en Actas del IX Congreso internacional de historia de América, Sevilla, Universidad de Sevilla, 1992, pp. 631-663; RODRÍGUEZ, Mario: El experimento de Cádiz en Centroamérica, 1808-1826, México, FCE, 1984, pp. 169-252; FERNÁNDEZ SARASOLA, Ignacio: "La Constitución...”, pp. 440-466; BROSETA, Salvador: "Realismo, autonomismo e insurgencia: el dilema americano en las Cortes del Trienio Liberal", Trienio. Ilustración y LIberalismo, $\mathrm{n}^{\circ} 41$ (2003), pp. 85-111; QUINZIANO, Franco: "España desde Argentina: monarquía y constitucionalismo en la Gazeta de Buenos Aires (1820-1821)", Spagna Contemporanea, $\mathrm{n}^{\circ} 16$ (1999), pp. 23-41; GÓMEZ VIZUETE, Antonio: "Los primeros ayuntamientos liberales en Puerto Rico (1812-1814 y 1820-1823)", Anuario de Estudios Americanos, $\mathrm{n}^{\circ} 47$ (1990), pp. 581-615; BREÑA, Roberto: "El primer liberalismo español y la emancipación de América: tradición y reforma", Revista de Estudios Políticos, n 121 (2003), pp. 257-290; y JAKSIC, Iván y POSADA, Eduardo (eds.): Liberalismo y poder. Latinoamérica en el siglo XIX, Santiago de Chile, Fondo de Cultura Económica, 2011.

77 Para la prensa ver MÁRQUEZ, Margarita y MENDOZA, Felicidad: "La emancipación hispanoamericana (1810-1825). El sistema informativo de la Gaceta de Madrid", y MONJE, Camino y LOPEZ, Amparo: "La guerra de la independencia hispanoamericana en El Universal, 1820-1823: Tratamiento informativo", en A. Gil Novales (ed.), Ciencia..., pp. 313-323 y 333-346; y VALLMITJANA, Lluisa: Emancipación de Hispanoamérica atraves de la prensa en Barcelona, 1820-1823. Aportación a su estudio, tesis doctoral inédita, Universitat de Barcelona, 1972.

78 EXAMEN imparcial de las disensiones de América con la España, de los medios de su reconciliación, y de la prosperidad de todas las naciones, Cádiz, 1812, y REPRESENTACIÓN hecha a S.M.C. el Señor Don Fernando VII en defensa de las Cortes, Londres, 1818, con reediciones en Londres (1819), Madrid (1820), Isla de León (1820), Valencia (1820), Barcelona (1820) y México (1820).

79 GIL NOVALES, Alberto: "La independencia de América en la conciencia española, 1820-1823", Revista de Indias, 39 (155-158) (1979), pp.235-265. Ver también CASTELOE, Michael P.: La respuesta a la Independencia. La España imperial y las revoluciones hispanoamericanas, 1810-1840, México, FCE, 1989; y CHUST, Manuel (ed.), La Trascendencia del Liberalismo en España y América, València, Biblioteca Valenciana, Generalitat Valenciana, 2004.
} 
referentes a América ${ }^{80}$. Las Cortes españolas insistieron en tratar el tema de América o Ultramar durante la legislatura ordinaria de 1820-1821, pero el gobierno moderado lo esquivó tanto tiempo como pudo y no fue hasta la legislatura extraordinaria de 18211822 que se trató de esta importante cuestión para el propio sistema político constitucional. Diversos diputados criticaron al primer gobierno constitucional por su indolencia respecto de los temas americanos. Entre ellos Guillem Oliver que culpó del deterioro de las relaciones económicas y políticas con Ultramar a la dejadez del ministerio: “de los solos documentos que obran en el expediente resultan cargos gravísimos contra el Ministerio y agentes suyos en este asunto, el más interesante de las Españas"81.

De hecho fueron las Cortes las que, el 3 de mayo de 1821, a petición de los diputados Felipe Fermín Paul y José M ${ }^{\mathrm{a}}$ Queipo de Llano, conde de Toreno, decidieron formar una Comisión especial que "propusiese lo más conducente, para concluir del modo mas acertado las disensiones que desgraciadamente aflijan a varios países de América”. Esta Comisión presentó su propuesta el 24 de junio, solicitando que el gobierno presentase urgentemente a las Cortes "las medidas fundamentales que creyese convenientes, así para la pacificación justa y completa de las provincias disidentes de América, como igualmente para asegurar a todas ellas el goce de una firmé y sólida felicidad". El día siguiente, el diputado don José Miguel Ramírez (electo por la provincia de Guadalajara de México) leyó la exposición de los diputados de Ultramar proponiendo quince medidas que consideraban eran las únicas "capaces dé restablecer la tranquilidad y asegurar la conservación y bien estar dé aquella grande e interesante parte de la monarquía, manteniendo la integridad de esta" ${ }^{\circ 2}$. Estas propuestas cayeron en saco roto y nunca se volvió a hablar de ellas, mientras que, como denunció el diputado Guillem Oliver, "a cada momento fueron aumentándose los males, peligros y apuros en nuestras Américas, y colmándose la ruina del comerció, marina e industria que las Españas fomentaran con su recíproca, libre y segura comunicación". Oliver criticó el "olvido" y la "pasividad" del gobierno español en este tema durante las Cortes Extraordinarias (1821-1822) ${ }^{83}$. Desde América la lectura que se hizo era la de que "no hay nada que esperar de España" ${ }^{\prime 4}$.

80 DECRETOS y ordenanzas de las Cortes generales y extraordinarias, y de las ordinarias, correspondientes a las atribuciones del Ministerio de Gobernación, de utilidad común a diferentes ciudades, villas y lugares de ellas, que el Rey se sirvió restablecer por Real decreto de 15 de Abril último, Madrid, 1820.

81 DSC, ext.1821-1822, t.III, pp. 2.293-2.294, sesión 141, de 18 de febrero. Ver JENSEN, Silvina: "El problema americano en el Trienio liberal. Análisis de las políticas de Ultramar de las Cortes españolas (1820-1823)", Trienio. Ilustración y Liberalismo, no 28 (1996), pp. 51-98; SÁNCHEZ ANDRES, Agustín: "La búsqueda de un nuevo modelo de relaciones con los territorios ultramarinos durante el Trienio Liberal (1820-1823)", Revista de Indias, n 57 (210) (1997), pp. 451-474; y NATER, Laura: "En busca de reconocimiento: La independencia de América Latina y la política española, 1820-1823", HMex, XIV, 4 (1996), pp. 705-735.

82 EXPOSICIÓN presentada a las Cortes por los Diputados de Ultramar en la sesión de 25 de junio de 1821, sobre el estado actual de las provincias de que son representantes y medios convenientes para su definitiva pacificación; con una noticia de los trámites que la precedieron y motivaron, Madrid, 1821. Ver también la sesión de 26 de junio de 1821 (DSC, 1821, t. III, pp. 2.515-2.558).

83 OLIVER, Guillem: "Voto adicional particular del señor diputado Oliver en el dictamen de la Comisión que entiende en los asuntos de Ultramar", Dictamen de la comisión nombrada para proponer medidas conducentes al bien y felicidad de ambas Américas, y votos adicionales de algunos individuos de la misma, Madrid, Imprenta de don Diego García y Campoy, 1822, pp. 4-7 (p. 5 para la cita).

84 RAMÏREZ, José Miguel: Nada hay que esperar de España, o esposición que leyó el Sr. D. [....], en la sesión de 25 de junio de 1821, México, Imprenta Imperial de D. Alejandro Valdés, 1821; NOTICIA de la mayor importancia. Consulta hecha al Rey de España por su Consejo de Estado sobre la independencia de América, México, Imprenta (contraria al despotismo) de D.J.M. Benavente y otros, 1821; M.J.U.: El amigo 
No fue hasta la sesión del 26 de octubre de 1821 que, de nuevo a propuesta del diputado Paul, las Cortes acordaron que el ministro de la Gobernación de Ultramar presentase a la mayor brevedad "las medidas que se considerasen mas conducentes y oportunas para conseguir la tranquilidad y bien de las Américas". En aquel momento las Comisiones de Comercio y Hacienda presentaban sus dictámenes "sobre el comercio de Nueva España, Guatemala, Yucatán y Filipinas".

Finalmente, el 17 de enero de 1822 y previa consulta al Consejo de Estado ( 7 de noviembre de 1821), el gobierno hizo públicas las ocho medidas que estimaba convenientes para "la conciliación de ánimos en las provincias de Ultramar". Un texto donde no se decía nada de "la desgraciada y apuradísima, situación de las Américas", y que según Oliver era la siguiente:

Las provincias españolas orientales del Rio de la Plata, se habían incorporado al reino unido de Portugal, Brasil y Algarbes; [...]; que la capital del Perú se hallaba ocupada por el ejército Chileno, y declarada [...] en absoluta independencia de la Metrópoli; que Cartagena baluarte principal e inexpugnable de Costa-firme se había rendido otra vez por falta de asistencia; que por igual abandono los preciosos restos del ejército del general Morillo se hallaban en la mas angustiada situación en Puerto Cabello; que esta plaza y aun la de Panamá necesitaban y pedían en vano socorro; que los mismos jefes, agentes o empleados del gobierno en Nueva España, Guatemala y Yucatán habían reconocido y firmado solemnemente la independencia: que a grito herido se oía esta voz en casi todos de los pueblos de América, aun en aquellos en que poco antes resanaban las de la paz, unión y gobierno; que después de la enajenación de las Floridas, de la declaración pública de intervención del presidente de los Estados Unidos y de diversos amagos de Otras potencias extranjeras, peligraba hasta la esperanza poder hacer convenios amistosos y de recíproca utilidad entre las provincias españolas de Ultramar y de Europa ${ }^{85}$.

Hubo que esperar hasta el mes de marzo de 1822 para que el secretario de Estado, Luis Valanzat, hiciera una detallada exposición de la situación de las "provincias españolas en Ultramar" en el cual se reconocía que la política española no había surtido los efectos deseados ${ }^{86}$.

Finalmente, el 25 de junio de 1822, las Cortes pudieron escuchar el dictamen de la Comisión de Ultramar, aunque, igual que pasaba con la Memoria del ministerio, no aportaba propuestas de actuación concretas, más allá de garantizar la libertad de movimientos de los americanos en España ${ }^{87}$. Los votos particulares nos permiten apreciar las divergencias entre los diputados, así Guillem Oliver pide que se exijan responsabilidades; José Ma Moscoso, el conde de Toreno y José Espiga niegan la independencia de México y rechazan la presencia en las Cortes de diputados de las provincias que se de-

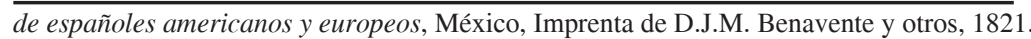

85 OLIVER, Guillem: "Voto adicional particular....", pp. 5-6.

86 "Esposición leída a las Cortes por el Sr. Secretario de Estado y del Despacho de la Guerra", DSC, 1822, pp.123-125, apéndice 2, a la sesión 9 de 4 de marzo.

87 DSC, 1822, t.III, pp.2.156-2.157, sesión 157 de 25 de junio. Se trata del Dictamen de la comisión nombrada para proponer medidas conducentes al bien y felicidad de ambas Américas, y votos adicionales de algunos individuos de la misma, Madrid: Imprenta de don Diego García y Campoy, 1822, que se redactó el 7 de febrero de 1822, aunque no se discutió por el pleno de las Cortes hasta el mes de junio. 
claran independientes; finalmente Tomàs Murphi (electo por México), Juan N. Gómez Navarrete (electo por Valladolid de Michoacán) y Felipe F. Paul (electo por Caracas) se mostraron partidarios de aceptar la realidad y negociar directamente con las nuevas autoridades: "Hubiéramos querido se manifestase clara y expresamente a los gobiernos establecidos en las provincias de Ultramar, que la España estaría dispuesta a convenir en su emancipación siempre que las bases en que esta se fundase, ofreciesen la garantía necesaria y al recíproco interés de unos y otro pueblos. E." 88 .

A finales de junio de 1822, Fernando VII, presionado por las Cortes y el gobierno se vio obligado a publicar un manifiesto respecto la situación en América donde se señalaba que la causa principal de las revueltas independentistas era la crisis que había provocado la guerra contra los franceses y en ningún caso podía atribuirse "al abuso de poder ni al peso de la opresión" $"$. Las propuestas de actuación consistían en negociar con los independentistas con el objetivo, se decía, de "ahorrar a aquellas regiones siglos enteros de miseria y de destrucción; impedir que la guerra y la anarquía atrasen los progresos de su civilización y cultura". Pero el aspecto más interesante del manifiesto real sobre Ultramar, era que se intentaba implicar al resto de países europeos. España se mostraba partidaria de terminar con el "monopolio comercial" con América, tanto para contentar a las colonias, como a las potencies europeas. A cambio, las potencias europeas debían denegar el reconocimiento oficial a los nuevos estados independientes. Unas propuestas que no tuvieron ningún éxito ni en el continente europeo, ni en Ultramar $^{90}$.

En definitiva la ecuación de los liberales era: Constitución = unidad + igualdad, es decir pensaban que con la proclamación de la Constitución, se reducirían las ansias de independencia y ello favorecería la unión, tal y como expresa Alonso Sáenz Díaz: "no se oirá ya entre nosotros la subversiva voz, soy Español, soy Americano, todos somos hijos de la amada Patria España y, por consiguiente, deberemos disfrutar de los placenteros beneficios que aquella difunde entre nuestros hermanos españoles" ${ }^{\prime 1}$. Pero, los gobiernos moderados de 1820-1821 fueron incapaces de plantear alternativas integradoras que garantizaran la unidad y la igualdad.

\footnotetext{
88 "Voto adicional de los señores Murfi, Navarrete y Paul al dictamen de la comisión de Ultramarr", DiICTAMEN de la comisión nombrada para proponer medidas conducentes al bien y felicidad de ambas Américas, y votos adicionales de algunos individuos de la misma, Madrid, Imprenta de don Diego García y Campoy, 1822, pp.11-12.

89 "Manifiesto que de orden de S.M., han pasado los Ministros y encargados de negocios de España a las Cortes de Europa" (publicado en el Diario de Barcelona, $\mathrm{n}^{\circ}$ 183, de 2 de julio de 1822, pp.1.739-1.744).

90 Ver M de PRADT: Examen du Plan presénté aux Cortés pour la reconaisance de l'indepéndence de l'Amérique Espagnole, París, Libraire Chez Bechet Ainé, 1822.

91 MANIFIESTO al pueblo español con motivo de la instalación de las Cortes el día 9 de julio de 1820, Madrid: Imprenta calle Bordadores, 1820. En el mismo sentido se expresa uno de los oficiales del ejército expedicionario a Ultramar a las órdenes de Riego y que encabeza la revolución: M.M.A.: Vindicación hecha en favor de los heroicos defensores de la patria que proclamaron la Constitución de la Monarquía del falso amancemillamiento de su honor que por una pretendida insubordinación se supone que cayeron por algunos que han tratado de oscurecer su loable conducta, Sevilla: Manuel de Aragón y Cia, 1820. Ver también la CARTA de un militar del ejército pacificador en Costa Firme de América en la que se inserta la proclama del general Murillo a sus soldados y el Perodo que un anciano español americano hizo a sus paisanos al recibir la célebre noticia de lo ocurrido en Madrid el día 9 de marzo último, Madrid, Imprenta de la viuda de López, 1820.
} 


\section{A MODO DE CONCLUSIÓN}

La revolución de 1820 y la restauración de la Constitución de 1812 en la monarquía española tuvieron un gran impacto en Europa y América. El rápido despliegue del sistema constitucional, el contenido democratizador de la Constitución de 1812 y el papel principal de las Cortes, incomodó a las potencias absolutistas europeas que la percibieron como una amenaza al sistema de la Restauración implantado hacía tan solo seis años.

La revolución española de 1820 encendía, a su pesar, la llama constitucional en la Europa de la Restauración y la amenazaba, o así lo sintieron el resto de monarquías absolutas. De hecho, la llama constitucional se propagó por Nápoles y Sicilia, por Portugal, por el Piamonte y empezó a prender en algunos lugares de Rusia, Prusia y Francia. Además, la Constitución de 1812 sirvió de punto de encuentro del liberalismo español y europeo, siendo editada en diversos idiomas y adoptada como propia por algunos países europeos.

La revolución liberal española fue bien acogida por importantes sectores de la población europea, pero movilizó en su contra a las monarquías absolutistas que unieron sus fuerzas para apagar las llamas constitucionales que amenazaban incendiar la Europa de la Restauración. Tan solo Inglaterra aceptaba el cambio político, aunque reclamaba moderación y modificación de la Constitución, ya que los intereses de Inglaterra respecto de España eran más económicos que políticos: las colonias españolas de Ultramar. El gobierno francés, en cambio, rápidamente desplegó un ejército en la frontera para evitar el "contagio" revolucionario y proteger a la contrarrevolución española. A partir de 1821 y una vez liquidados los régimen constitucionales italianos, se comenzó a hablar claramente de una posible invasión de España para acabar con el sistema constitucional. Mientras tanto, la Constitución española de 1812 se convertía en "la palabra, el nombre, el estandarte, en torno al cual se reunían los liberales".

En América, la segunda proclamación de la Constitución tuvo un impacto menor, ya que los procesos de independencia de las antiguas colonias españolas estaban en pleno desarrollo. La dejadez de los primeros gobiernos constitucionales moderados, no hizo sino empeorar las cosas, dificultando cualquier tipo de acuerdo. Las Cortes intentaron por activa y por pasiva presionar al gobierno, pero este dilató todo lo que pudo el asunto y cuando se discutió en las Cortes el tema de Ultramar, en 1822, ya era demasiado tarde.

La Constitución de 1812 fue ampliamente difundida en América y ampliamente aceptada como modelo, lo que falló fue el sistema, ya que buena parte de los americanos que tenían protagonismo político, no confiaban en llegar a un acuerdo satisfactorio con el gobierno y las Cortes peninsulares. Frente a la posición independentista, que contaba con el apoyo de algunos constitucionales peninsulares, la mayoría constitucional propuso negociar alrededor de la fórmula "unión con constitución". Pero esta propuesta era muy difícil de plasmar y realizar en aquel contexto, y la restauración absolutista de 1823 cerró cualquier posibilidad de negociación. 